\title{
START-UPS AND INTERNATIONALISATION: THE CASE OF ROMANIA. PART 2. EMPIRICAL RESEARCH
}

\author{
Anamaria Diana Herte*, Monica Cenan (Ciucoș) \\ Doctoral School of Economic Sciences, Faculty of Economic Sciences, University of \\ Oradea, Oradea, Romania \\ dianaherte89@gmail.com \\ monica.ciucos@yahoo.com
}

\begin{abstract}
Companies' creation and growth are a fervently debated topic in the literature and economic policies, at least for the fact that they are related to maintaining a critical number of active companies, an essential aspect of the functioning of the economy and society. Growth is associated with overcoming the stage of survival and ensures the development and consolidation of existing companies, meanwhile the establishment of the new ones means the replacement of those that disappear from the economic landscape. The launch and expansion of young companies could lead to a positive balance in terms of employment, income, incentive of demand to other sectors and regions, boosting their development. New firms are often associated with innovation and technological change, competitiveness and competition on the market. The survival, growth and consolidation of companies occurs not only as a result of quantitative accumulations, but also as a result of the incorporation of new technologies, an open attitude towards innovation, whether it is technical, managerial or commercial. Growth is therefore a normal phenomenon in the life of a company, which must be encouraged and supported by public measures as part of a smart and forward-looking economic policy. Growth may be local, but it usually takes place at national, regional and international levels. In the first part of this article we have presented and discussed the theoretical background as it results of previous researches and official studies and reports, internationalization opportunities and some features and trends of internationalization of companies in the EU, and Romania, respectively. We now present our investigation to determine whether, and to what extent, internationalisation is relevant to start-ups, if there is a possible correlation between the 6 selected indicators of internationalisation as revealed by World Bank Data on one hand, and the number of start-ups in Romania on the other hand.
\end{abstract}

Keywords: start-ups, internationalisation, World Bank indicators, Romania.

JEL classification: M13, O19, F23.

\section{Introduction}

The European Commission (2020a) considers SMEs to be the "backbone" of the European economy; they account for $99 \%$ of all EU businesses, generating around $85 \%$ of new jobs in the last five years and covering two thirds of all EU private sector's jobs. SMEs and entrepreneurship are the vital element in ensuring growth, innovation, job creation and social integration in the EU (European Commission, Internal Market, Industry, Entrepreneurship and SMEs, 2020).

In the more than 10 years since Romania became a member of the European Union, significant efforts have been made to adapt policies and strategies to the single market, to

* Corresponding author: Anamaria Diana Herte 
create better framework conditions to initiate and develop new businesses and to provide access to financial and human resources, support structures and market opportunities. Among these, internationalization is particularly important for the SME sector because it opens up new markets and has the potential to significantly stimulate their competitiveness and growth (European Union Open Data Portal, 2015), (Bădulescu \& Petria, 2011), (Badulescu et al, 2014). Internationalization can lead to gains in competitiveness at the enterprise level, which can ultimately translate into improved economic performance at national and European level (European Commission, 2010, p. 57), (European Commission, 2014).

There are several features of the internationalization of European companies: the size, age and experience of SMEs are important factors in their desire and ability to internationalize:

- The larger the enterprise, the more it tends to internationalize, (import-export operations are found in $24 \%-28 \%$ of micro-enterprises and up to $53 \%-55 \%$ in the case of mediumsized enterprises) (European Commission, 2010, p. 5).

- Export and import activities increase as an enterprise ages, from about $15 \%$ of enterprises by the age of 4 , to almost $30 \%$ of enterprises that are at least 25 years old (European Commission, 2010: 6).

- In terms of experience, very few internationally inactive SMEs intend to start international activities in the near future.

SMEs usually start with imports, and some sectors tend to be more suitable for internationalization than others. Trade, manufacturing, transport and communications, and research are the most "international" sectors. Businesses involved in e-commerce are more active internationally. The diversity and novelty of the means of sale (including online) are positively correlated with the activity on the export or import markets, the internet facilitating for SMEs of all sizes overcoming some of the barriers to internationalization (European Commission, 2010, p. 7), (European Commission, 2014), (Badulescu, \& Badulescu, 2012). In other words, although internationalization is more than necessary for the development of the small and medium enterprise sector, and current trends of globalization, expansion of the digital world, stimulation of innovation, but also the consistent support coming from EU, are favourable to European SMEs' internationalization, the start-up situation does not become automatically favourable. Thus, start-ups are, mostly, very small companies that cannot benefit from the advantage of size and experience. On the other hand, the chance of digitalization and expansion of the Internet and global communications, the increase of the Information technology exports and High technology exports shares in total exports could represent a chance in the expansion and consolidation of the start-up sector.

This article is the second part of the research investigating the relationship between number of start-ups and internationalisation of the firms for the case of Romania after 2000. While in the first article we have presented and discusses the theoretical background as well as results of previous researches in the literature, we now present our investigation. The article is organized as follows: in section 2 we present the data and general methodology, in section 3 we present the correlations between the number of Romanian start-ups and each of the 6 measures for internationalisation, in section 4 we investigate the direction of the relations, in section 5 we present the regression results. In the final section we conclude and present the implications of our findings.

\section{Data and methodology}

We used data retrieved from Romanian statistics, i.e. Tempo online database (Institutul Naţional de Statistică, 2020), Eurostat (2020) and World Bank (The Global Economy, 2020). We used data available for the timespan 2000-2018 for: Number of start-ups, considered the dependent variable, and the following: Trade openness, Exports of goods and services, 
Imports of goods and services, Foreign direct investment, Information technology exports, High technology exports considered independent variables. There are some missing values from the series, i.e. for Information technology exports it is missing the value for 2018, and for High technology exports the available data only ranges from 2007 to 2018 . For the Number of start-ups, we eliminated the values for 2008 and 2014, as they were incorrect in the original source.

As methods, in order to investigate possible relationships between number of start-ups and internationalisation of the firms for the case of Romania after 2000, first we performed Spearman correlations to obtain an overview of possible associations. Secondly, we investigated the existence of Granger causality and the direction of the relationship. Thirdly, we created the simple linear regression models and thus we identified which model can be built in order to make predictions.

To perform the statistical analyses, we used R 3.6.3 and the addons: Imtest, forecast and corrplot, as well as MS Excel for basic data manipulation. In Table 1, we prefer mentioning p-values below 0.15 - an „almost significant” association can be a false negative due to insufficient data for some variables, and can be confirmed by other studies with larger samples.

\section{Analysis of possible linear relationships}

In order to determine whether, and to what extent, internalisation is relevant to start-ups, we initially analysed the possible correlations between the 6 indicators of internationalisation (the independent variables), on one hand, and the number of start-ups (the dependent variable) on the other hand.

It is evident that the number of start-ups does not follow a normal distribution (Shapiro-Wilk p-value $<0.05$, see also the quantile-quantile plot in Figure 1). Subsequently, we performed nonparametric Spearman rank correlations, which do not require normally-distributed variables.

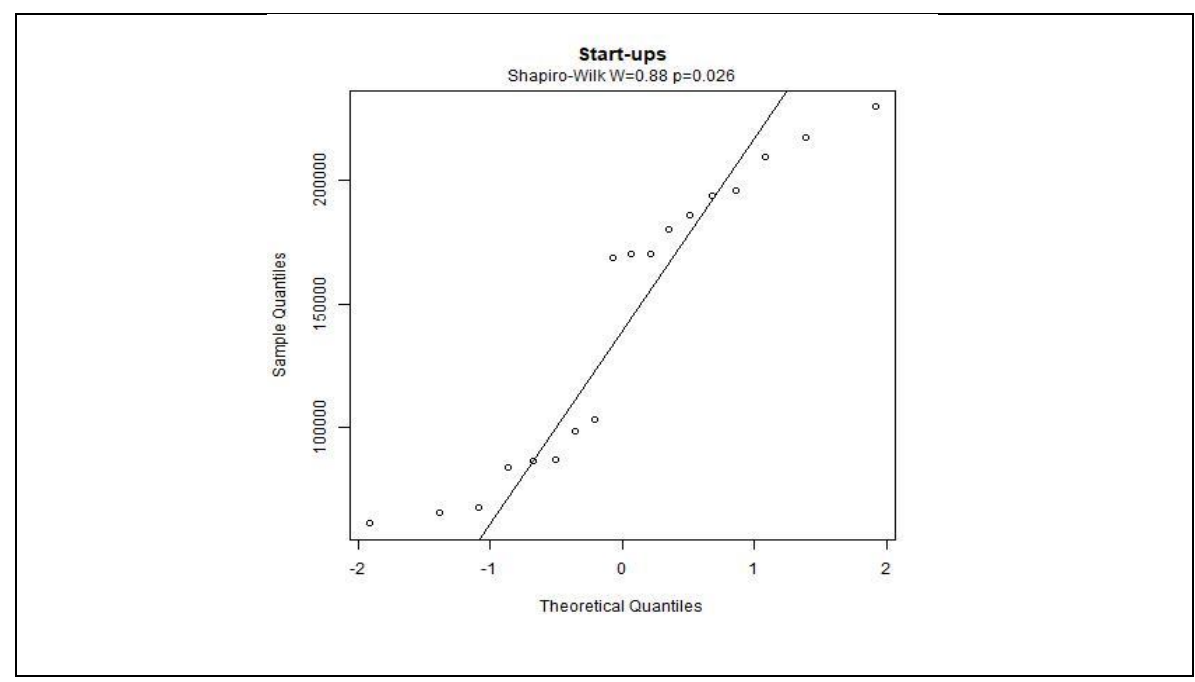

Figure 1. Quantile-quantile plot, Shapiro-Wilk W statistic and p-value for number of startups 
The results are graphically summarized in Figure 2. Positive correlations are represented by blue discs, and negative correlations in red. The color intensity and the discs' diameter is proportional to the magnitude of the correlation.

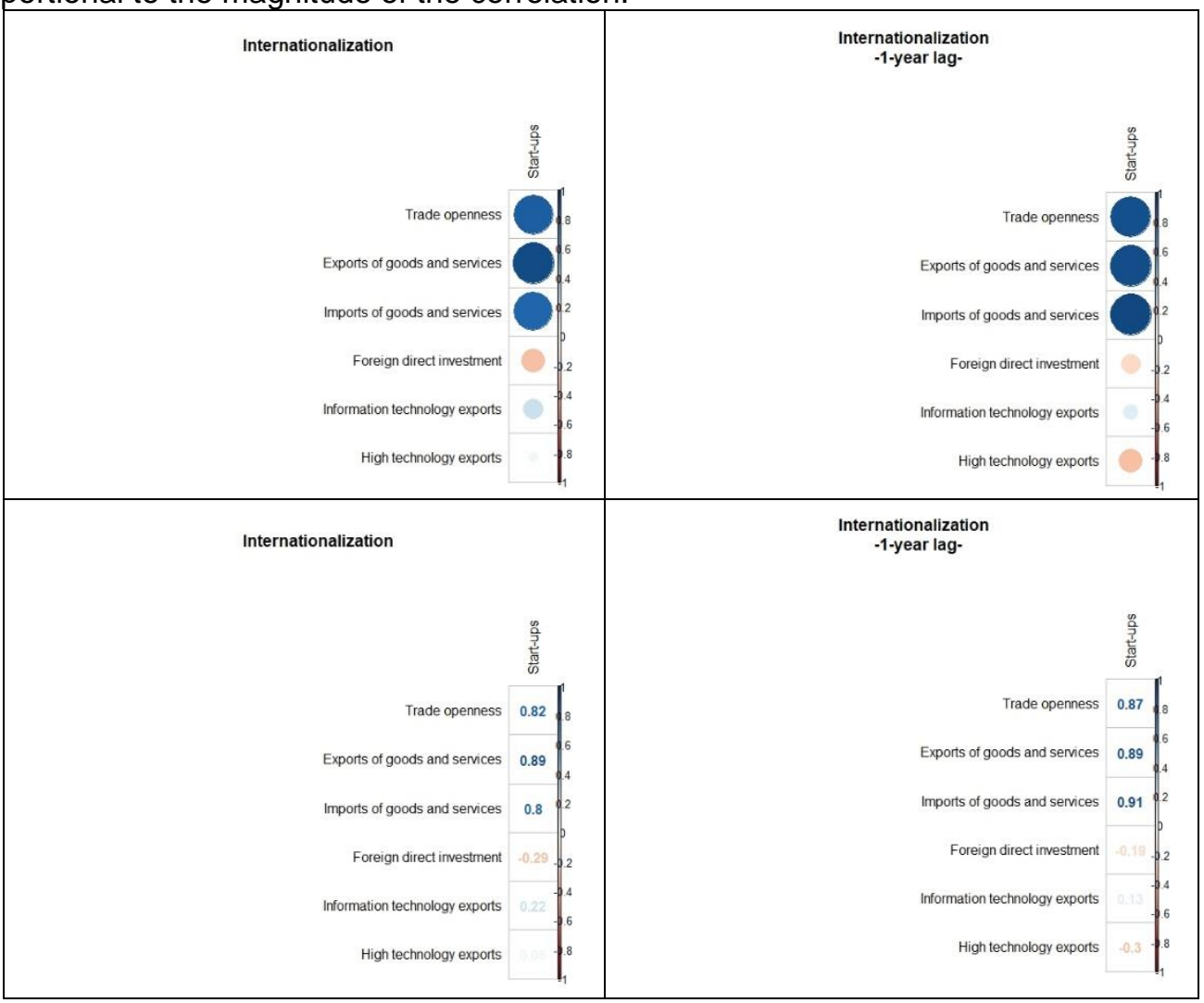

Figure 2. Plots of correlation matrix for internationalisation indicators and number of startups, România, 2000-2018

Additionally, Table 1 presents the results of each correlation. Significant correlation coefficients are marked with *. Moreover, since modifications in some dependent variables can have delayed effects, only noticed in the following year, we attempted to identify correlations between dependent values in year $n \mathrm{v}$. the number of start-ups in year $n-1$. The results are presented in Table 1, in the „1-year lag” columns.

Table 1. Spearman correlations

\begin{tabular}{|l|c|c|c|c|}
\hline \multirow{2}{*}{\multicolumn{1}{c|}{ Independent variable }} & \multicolumn{2}{c|}{ Current } & \multicolumn{2}{c|}{ 1-year lag } \\
\cline { 2 - 5 } & Spearman $\boldsymbol{\rho}$ & Value $\mathbf{p}$ & Spearman $\boldsymbol{\rho}$ & Value $\mathbf{p}$ \\
\hline Trade openness & $0.82^{*}$ & $<0.001$ & $0.87^{*}$ & $<0.001$ \\
\hline Exports of goods and services & $0.89^{*}$ & $<0.001$ & $0.89^{*}$ & $<0.001$ \\
\hline Imports of goods and services & $0.8^{*}$ & $<0.001$ & $0.91^{*}$ & $<0.001$ \\
\hline Foreign direct investment & -0.29 & $>0.15$ & -0.19 & $>0.15$ \\
\hline Information technology exports & 0.22 & $>0.15$ & 0.13 & $>0.15$ \\
\hline High technology exports & 0.05 & $>0.15$ & -0.3 & $>0.15$ \\
\hline
\end{tabular}


As it is readily apparent in Table 1, similar effects are described for both current and 1-year lagged correlations: trade openness, exports and imports of goods and services are significantly and positively associated with the number of start-ups, while foreign direct investment, information technology and high-technology exports are not significantly associated with the number of start-ups.

\section{Direction of causality}

Before building regression models to predict changes in the dependent variable caused by modifications in one independent variable, we attempted to confirm the direction of dependence using Granger tests at 1-year lags (Granger, 1969). It should nonetheless be stated that no statistical technique can prove causality, the Granger test only being able to confirm temporal succession (i.e. that a change in the value of the independent variable at present will determine a future modification in the value of the dependent value, and not vice-versa) - see for example (Leamer, 1985)

Because the Granger test can only be applied to stationary time series, we tested for this property by employing the Ljung-Box test ( $p$-value $>0.05$ is consistent with stationarity) (Ljung, Box, 1975). The tests were performed on both the original and transformed (logdifferenced) series. The aspect and Ljung-Box results for each time series are plotted in Figure 3.

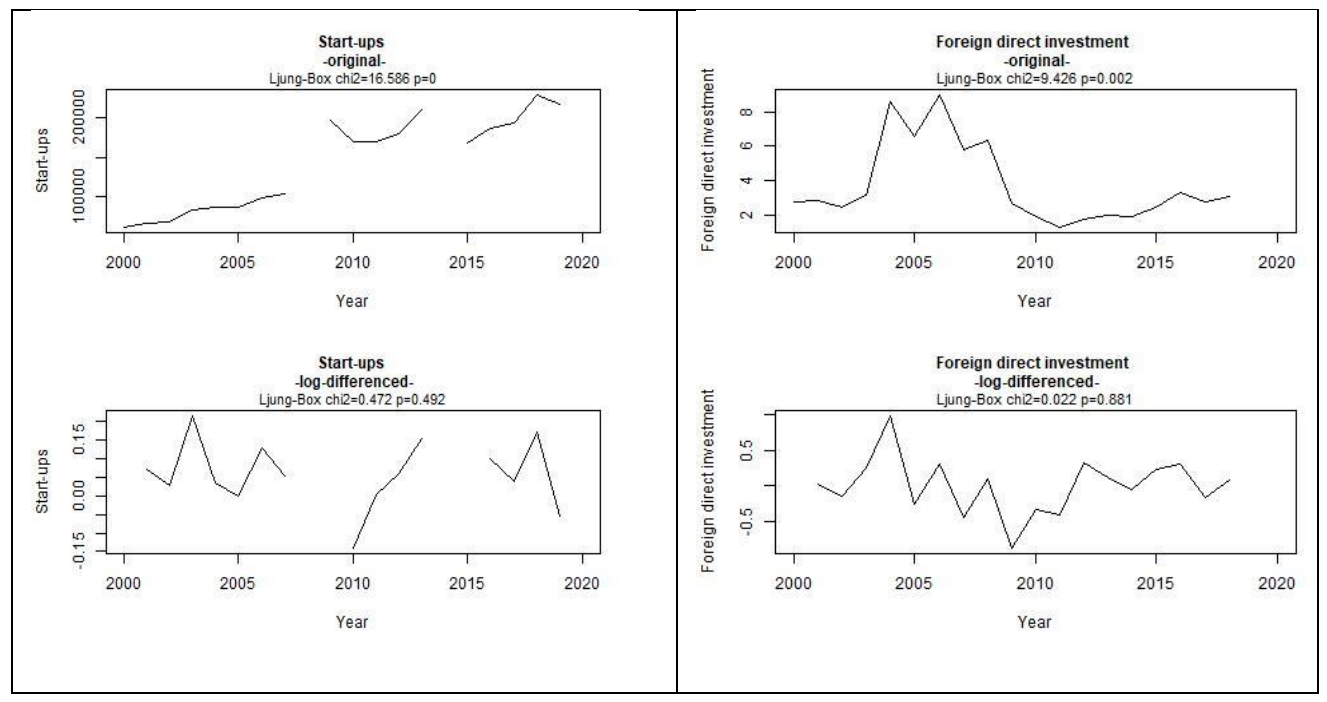




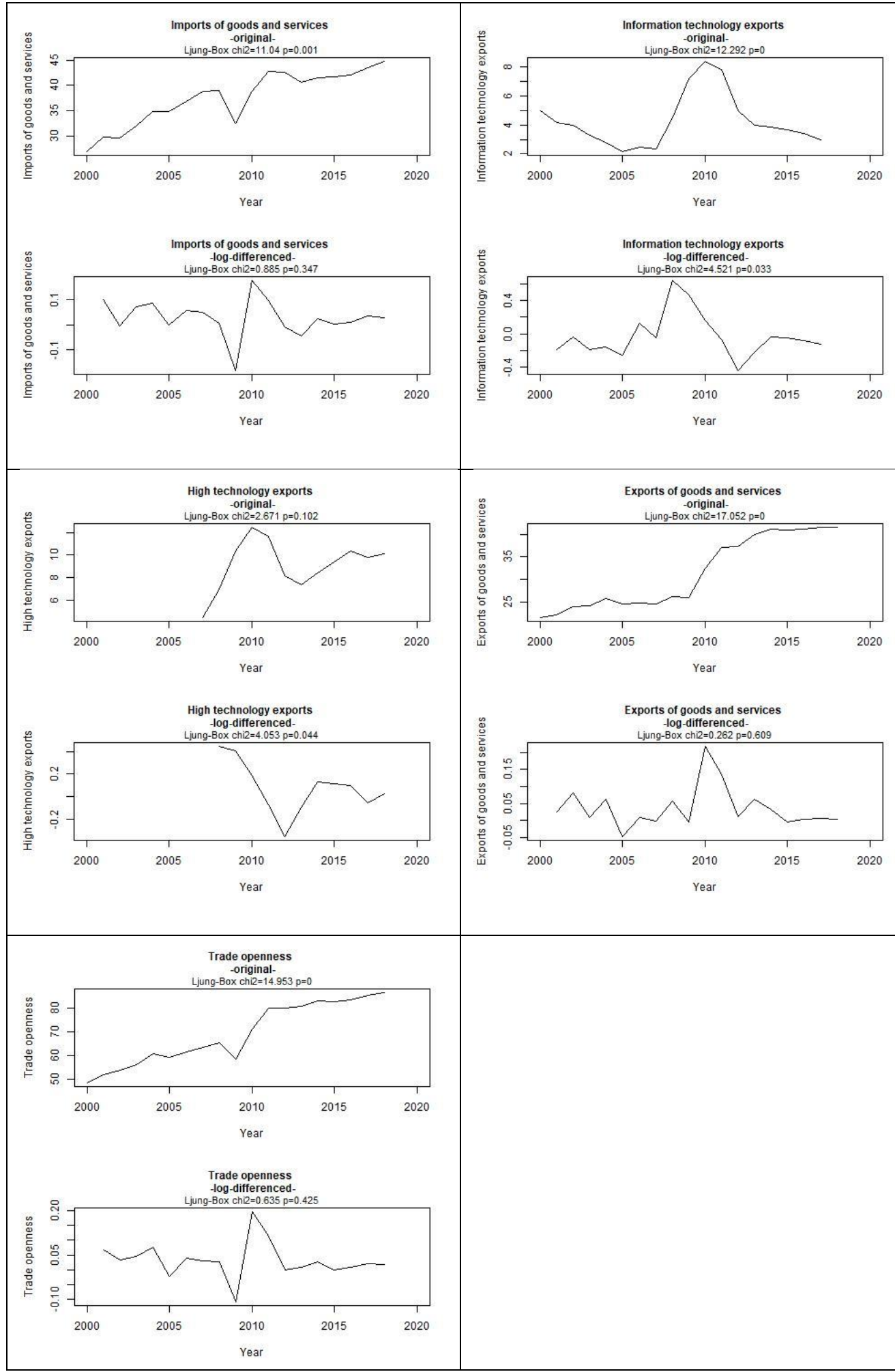

Figure 3. Plot of original and transformed time series and Ljung-Box test results 
It can be noticed that neither the dependent variable time series (number of start-ups), nor most independent variable time series, are stationary. Consequently, we performed the Granger tests on the log-differenced time series. The results are presented in Table 2.

Table 2. Granger test results, treating the number of start-ups as dependent („Direct causality”), then independent („Inverse causality”)

\begin{tabular}{|l|c|c|c|c|}
\hline \multirow{2}{*}{ Variable } & \multicolumn{2}{c|}{ Direct causality } & \multicolumn{2}{c|}{ Inverse causality } \\
\cline { 2 - 5 } & F statistic & p-value & F statistic & p-value \\
\hline Trade openness & 2.233415 & $>0.15$ & 0.059874 & $>0.15$ \\
\hline $\begin{array}{l}\text { Exports of goods and } \\
\text { services }\end{array}$ & 0.080858 & $>0.15$ & 0.428751 & $>0.15$ \\
\hline $\begin{array}{l}\text { Imports of goods and } \\
\text { services }\end{array}$ & 4.953211 & 0.0502 & 0.001497 & $>0.15$ \\
\hline Foreign direct investment & $<0.001$ & $>0.15$ & 4.252949 & 0.0661 \\
\hline $\begin{array}{l}\text { Information technology } \\
\text { exports }\end{array}$ & 1.41455 & $>0.15$ & 0.01211 & $>0.15$ \\
\hline High technology exports & 2.882463 & $>0.15$ & 0.875999 & $>0.15$ \\
\hline
\end{tabular}

We were unable to demonstrate the existence of Granger causality for any variable. However, the results suggest a possible "direct” causality for Imports of goods and services, and a possible inverse dependence for Foreign direct investment.

\section{The analysis of linear relationships}

In order to predict the evolution of the number of start-ups (the dependent variable) as a function of individual indicators of internalisation, we constructed simple linear regression models: $\quad$ Number of start - ups $=a \cdot$ Dependent variable $+b+\epsilon \quad, \quad$ where $\mathrm{a}=$ regression coefficient, $\mathrm{b}=$ intercept, $\epsilon=$ normally-distributed error term). The results are summarized in Table 3 as follows: coefficient (standard error), intercept (standard error), Fstatistic (degrees of freedom), adjusted $\mathrm{R}^{2}$, $\mathrm{p}$-value for F-test.

Table 3. Regression analyses for the number of start-ups

\begin{tabular}{|l|c|c|c|c|c|}
\hline Independent variable & $\mathbf{a}(\mathbf{s e})$ & $\mathbf{b}(\mathbf{s e})$ & $\mathbf{F}(\mathbf{d f})$ & $\begin{array}{c}\text { Adjust } \\
\mathbf{e d ~ R}^{\mathbf{2}}\end{array}$ & $\mathbf{p}$ \\
\hline Trade openness & $3833(562)$ & $\begin{array}{c}-123518 \\
(39101)\end{array}$ & $\begin{array}{c}46.56 \\
(1,15)\end{array}$ & 0.74 & $<0.001$ \\
\hline $\begin{array}{l}\text { Exports of goods and } \\
\text { services }\end{array}$ & $6380(912)$ & $\begin{array}{c}-60069 \\
(29272)\end{array}$ & $\begin{array}{c}48.971 \\
(1,15)\end{array}$ & 0.75 & $<0.001$ \\
\hline $\begin{array}{l}\text { Imports of goods and } \\
\text { services }\end{array}$ & $8426(1591)$ & $\begin{array}{c}-175173 \\
(59889)\end{array}$ & $\begin{array}{c}28.051 \\
(1,15)\end{array}$ & 0.628 & $<0.001$ \\
\hline $\begin{array}{l}\text { Foreign direct } \\
\text { investment }\end{array}$ & $\begin{array}{c}-11386 \\
(5705)\end{array}$ & $\begin{array}{c}180669 \\
(24690)\end{array}$ & $\begin{array}{c}3.984 \\
(1,15)\end{array}$ & 0.157 & 0.064 \\
\hline $\begin{array}{l}\text { Information } \\
\text { technology exports }\end{array}$ & $\begin{array}{c}11387 \\
(6925)\end{array}$ & $\begin{array}{c}84321 \\
(32368)\end{array}$ & $\begin{array}{c}2.704 \\
(1,14)\end{array}$ & 0.102 & 0.122 \\
\hline $\begin{array}{l}\text { High technology } \\
\text { exports }\end{array}$ & $6888(4496)$ & $\begin{array}{c}116008 \\
(43450)\end{array}$ & $\begin{array}{c}2.347 \\
(1,8)\end{array}$ & 0.13 & $>0.15$ \\
\hline
\end{tabular}

As described in Table 3, 3 predictors show at least moderate $\left(R^{2}>0.5\right)$ performance: Trade openness, Exports of goods and services, Imports of goods and services. As we notice în the Table 3, there are 3 predictors with moderate or better performances, namely: Trade 
openness, Exports of goods and services, Imports of goods and services. We checked whether the models follow the assumptions of linear regression graphically, by means of diagnostic plots, and by employing the relevant statistical tests. The diagnostic plots and tests are presented in Tables 4 to 6 (Annexes) for each of the 3 regression models.

Examining the regression diagnostic results, we notice that no model entirely respects the premises of a linear regression model. However, given that variables "Trade openness" and "Exports of goods and services" slightly respect the four criteria, we consider that we can employ the two variables for making predictions.

Consequently, we have the following models:

1. Model Start - ups $=a \cdot$ Trade openness $+b$ :

- The variation of "Trade openness" explains a large (i.e. 74\%) proportion of the variation of the number of start-ups.

Increasing by $1 \%$ the value of "Trade openness" is associated with an increase of about 3,830 of the number of start-ups.

- Granger test failed to prove the existence of a short term (1 year) causality.

2. Model Start - ups $=a \cdot$ Exports of goods and services $+b$ :

- The variation of "Exports of goods and services" explains a large (i.e. $72.5 \%$ ) proportion of the variation of the number of start-ups.

- Increasing by $1 \%$ the value of "Exports of goods and services" is associated with an increase of about 6,380 of the number of start-ups.

- Granger test failed to prove the existence of a short term (1 year) causality.

After identifying the two satisfactory predictors, we attempted to perform a multiple regression analysis for the combination of "trade openness" and "exports of goods and services" as independent variables, but the results indicated lack of statistical significance for both predictors. Consequently, we had to limit the analysis to simple regressions, which present statistical significance and satisfactory predictive performance.

\section{Conclusions}

International markets are an important source of growth for small and medium-sized enterprises (SMEs), however, there are relatively few EU SMEs doing business beyond Europe. According to the European Commission (2020) only 600,000 SMEs, employing around 6 million people, export goods outside the EU. Within this segment, the number and share of start-ups is even smaller. In European Union policies, increasing the internationalization of SMEs is essential for European competitiveness, growth and innovation, but the effects on the training of young, ambitious and high-tech firms are relatively limited. Even if the European Commission says that SMEs are the backbone of the European economy, they can truly become a vehicle for restoring growth in the EU, if internationalization is to be done on a large scale (ECSIP Consortium, 2013), involving a wide variety of small young firms from all EU member states.

In this paper, we attempted to identify possible associations between the number of startups and various indicators of internationalization. Initially, the use of linear, nonparametric correlations, suggested the existence of positive relationships between the number of startups and indicators of trade openness and both imports and exports of goods and services, relationships which hold both for synchronous, and 1-year-lagged correlations.

However, we were unable to unequivocally demonstrate the direction of causality, with the exception of an "almost-significant" direct causality regarding imports of goods and services (i.e., that imports influence the number of start-ups, and not vice-versa), which we consider that it can eventually be confirmed by a larger study or as data for more years becomes available. Moreover, a linear regression model for the number of imports failed to observe the model's requirements. However, the other two independent variables satisfy, to some 
extent, the model's criteria, and, despite the lack of proof for causality, can be used to estimate the number of start-ups.

\section{References}

Badulescu, A. \& Badulescu, D., 2012. Entrepreneurship and Local Resources. In: D. Leslie, ed. Tourism Enterprises and the Sustainability Agenda across Europe. UK: Ashgate Publishing, pp. 151-168.

Badulescu, D. \& Petria, N., 2011. Collateral's Importance in SMEs Financing: What Is The Banks' Response? Some Evidence for Romania. The Annals of the University of Oradea. Economic Sciences, XX(1), pp. 256-260.

Badulescu, D., Simut, R. Badulescu, A., 2014. Looking for better financing: a quantitative approach on collateral importance in SMEs relationship lending, Conference Proceedings of the 8th International Economic Conference "International Days of Statistics and Economics", Prague, September 11-13, pp. 43-52.

ECSIP Consortium, 2013. Study on Support Services for SMEs in International Business. Final Report, Amsterdam: ECSIP.

European Commission, Internal Market, Industry, Entrepreneurship and SMEs, 2020. Entrepreneurship and Small and medium-sized enterprises (SMES). Available at: https://ec.europa.eu/growth/smes en [Accesed 1108 2020].

European Commission, 2010. Business \& Policy Research, 2010. Internationalisation of European SMEs, final report, Brussels: DG Enterprise and Industry.

European Commission, 2014. Guidebook Series How to support SME Policy from Structural Funds. Supporting the Internationalisation of SMEs, Luxembourg: Office for Official Publications of the European Union, https://doi.org/10.2769/94863.

European Union Open Data Portal, 2015. Flash Eurobarometer 421: Internationalisation of Small and Medium-sized Enterprises. Available at: https://data.europa.eu/euodp/en/data/dataset/S2090 421 ENG [Accessed 0304 2020].

Eurostat, 2020. Business demography. Available at:
https://ec.europa.eu/eurostat/web/structural-business-statistics/entrepreneurship/businessdemography, [Accesed 0304 2020].

Granger, C.W.J., 1969. Investigating Causal Relations by Econometric Models and Crossspectral Methods, Econometrica, 37 (3), pp. 424-438, https://doi.org/10.2307/1912791.

Institutul Naţional de Statistică, 2020. Demografia Intreprinderilor. Available at: http://statistici.insse.ro:8077/tempo-online/\#/pages/tables/insse-table_[Accessed $21 \quad 07$ 2020].

Leamer E.E., 1985. Vector autoregressions for causal inference? Carnegie-Rochester Confer Series Public Policy, 22(C), pp. 255-304.

Ljung, G.M., Box, G.E.P., 1978. On a measure of lack of fit in time series models, Biometrika, 65 (2), pp. 297-303, https://doi.org/10.1093/biomet/65.2.297.

The Global Economy, 2020. Download economic data. Available at: https://www.theglobaleconomy.com/download-data.php [Accessed 1504 2020].

\section{Bio-note}

Anamaria Diana Herte graduated at University of Oradea, Faculty of Economic Sciences and now is Ph.D. student at the same university. In her doctoral research she focuses on the Start-ups in the contemporary economy. Monica Cenan Ciucos is Ph.D. student at University of Oradea. Her doctoral research is focused on Entrepreneurial performance and economic development in Romania. 


\section{Annexes}

Table 4. Diagnostic plots for "Trade openness"

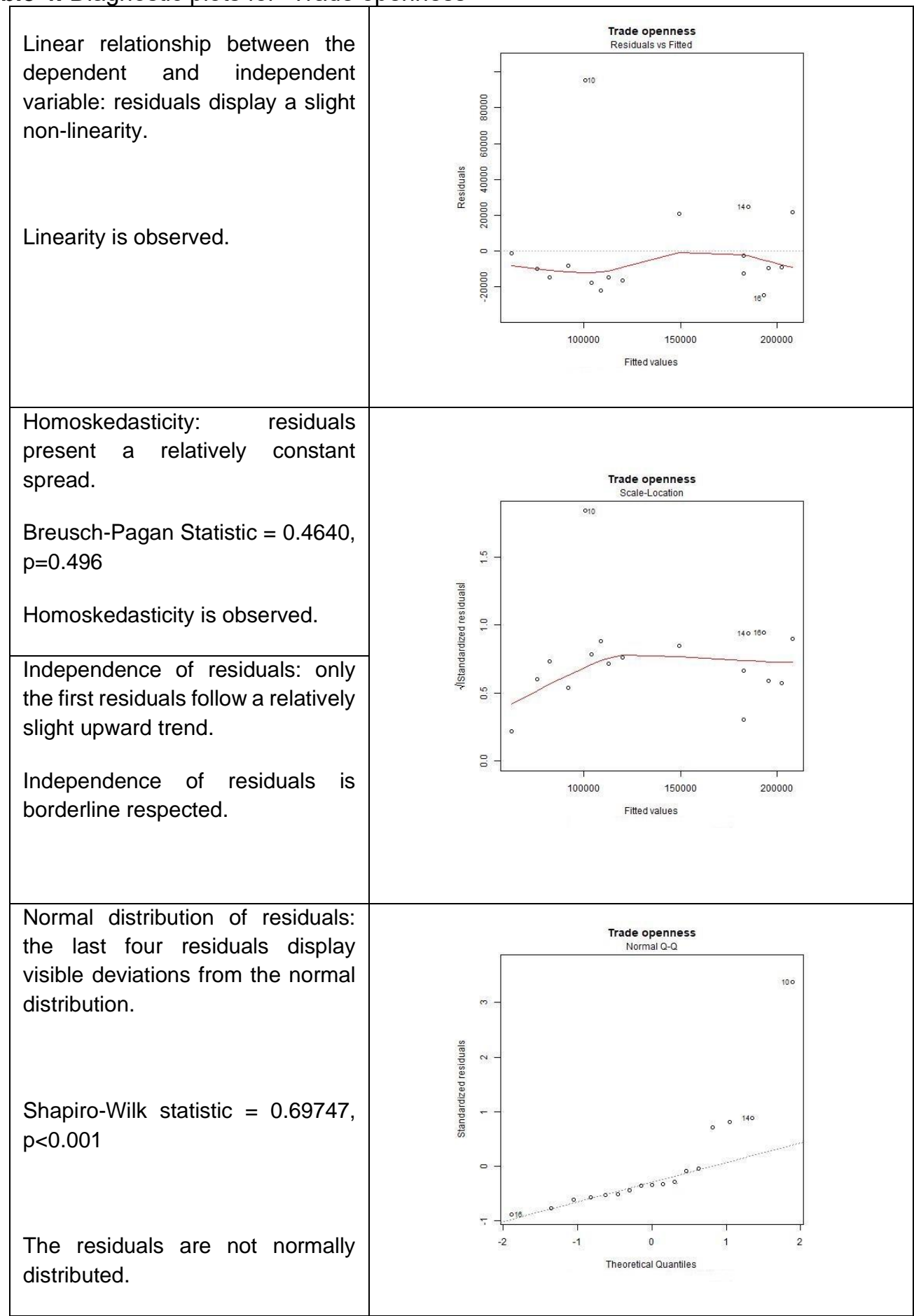


Table 5. Diagnostic plots for "exports of goods and services"

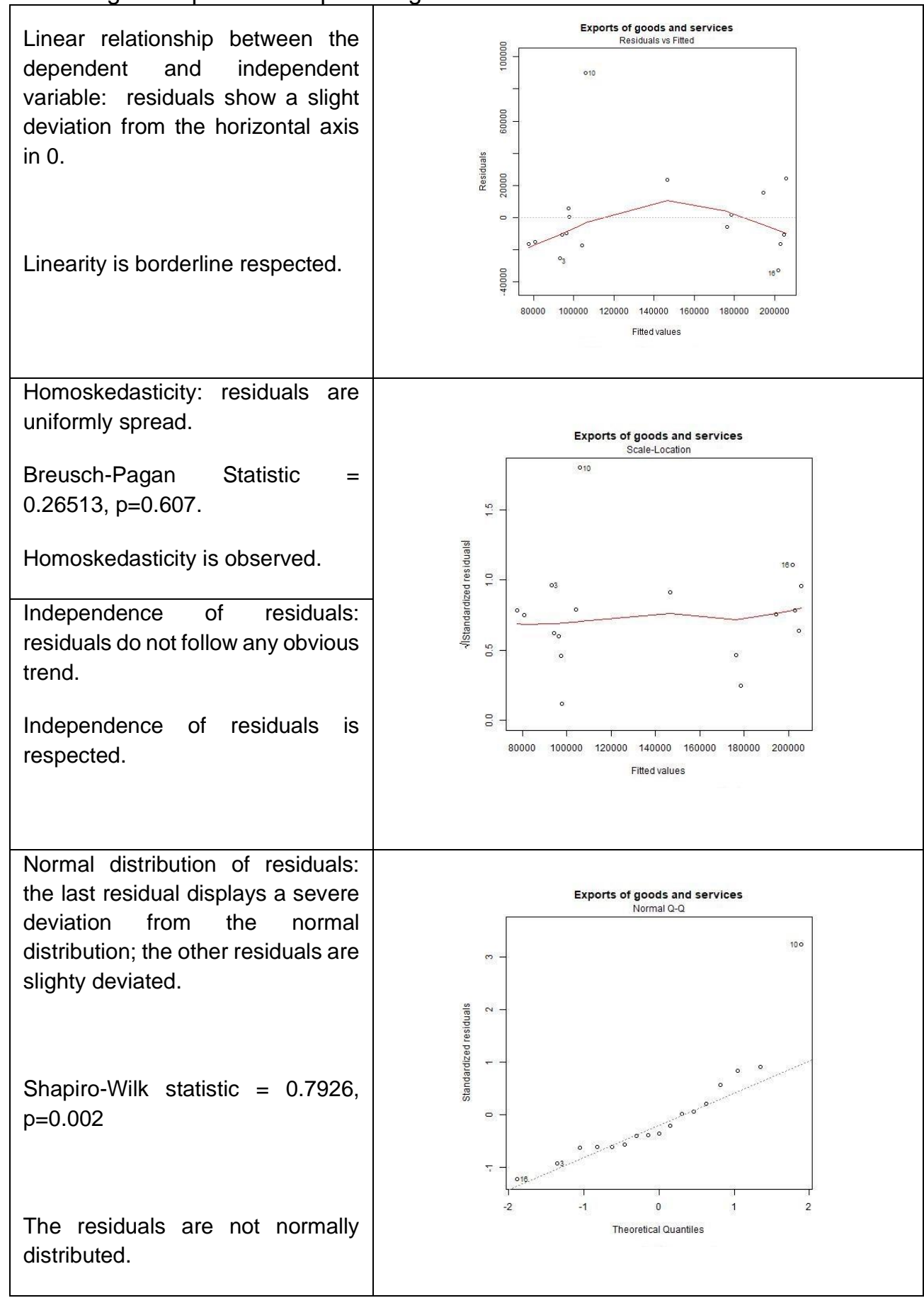


Table 6. Diagnostic plots for "imports of goods and services"

Linear relationship between the dependent and independent variable: a severe deviation from linearity is noticed.

Linearity is not respected.

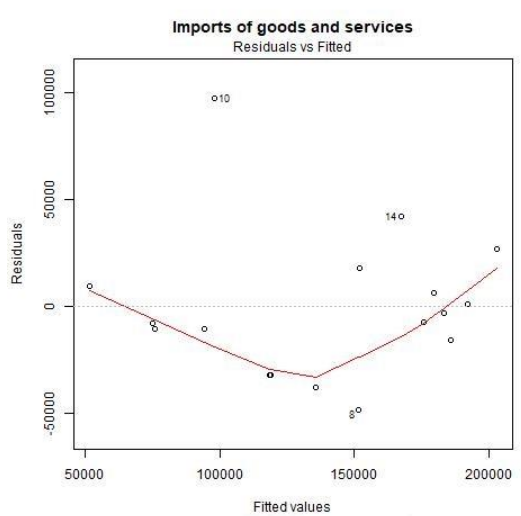

Homoskedasticity: intermediate

residuals are more highly spread.

Breusch-Pagan statistic $=0.540, \mathrm{p}=$ 0.462 .

Homoskedasticity is observed.

Independence of residuals: residuals display an obvious upward, then downward trend.

Independence of residuals is not respected.

Normal distribution of residuals: the first and last residuals display deviations from the normal distribution; the other residuals closely follow the normal distribution.

Shapiro-Wilk statistic $=0.899, \mathrm{p}=$ 0.065

The residuals are borderline normally distributed.
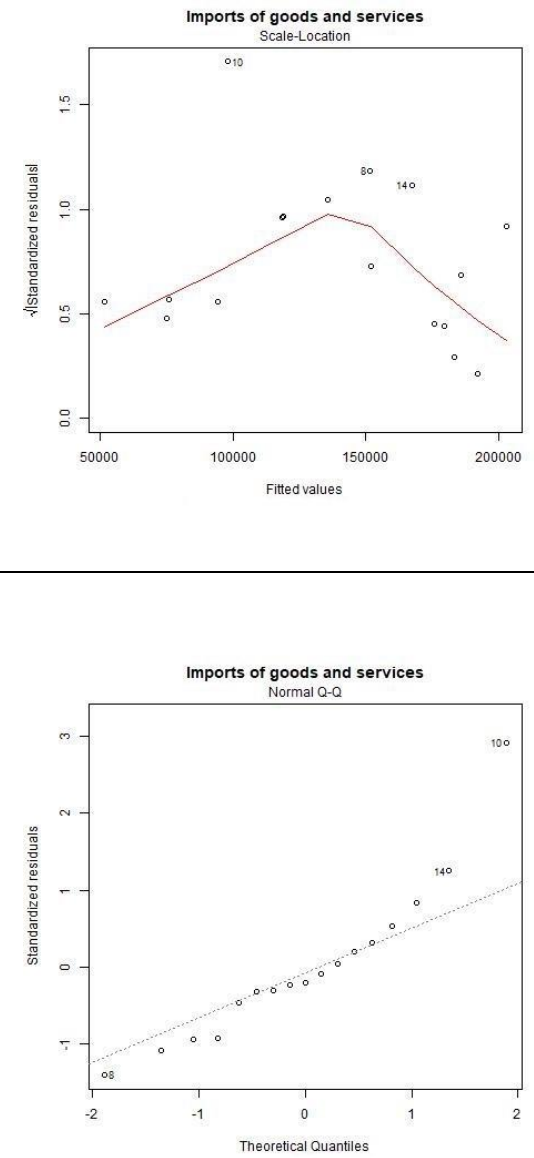